\title{
Health care experiences in infancy and subsequent frequent illness in 1-year-old children
}

\author{
Ruth Ertmann", Volkert Siersma, Susanne Reventlow, Margareta Söderström
}

Department of General Practice, Research Unit for General Practice in Copenhagen, Copenhagen, Denmark;

${ }^{\#}$ Corresponding Author: ruth@sund.ku.dk

Received 29 November 2012; revised 30 December 2012; accepted 6 January 2013

\section{ABSTRACT}

Background: Parents of infants suffering from frequent episodes of illness demand more acknowledgement from general practice with regard to their observations of these illnesses, which is evident from their tendency to book multiple consultations. Aim: To identify factors relating to illness and health-care experiences in infancy which predict frequent episodes of illness in toddlers. Design of study: A retrospective questionnaire and a prospective diary study including 183 infants born in February 2001 in a district of the capital region of Denmark. Setting: Denmark, primary care. Methods: Infants were recruited from a birth cohort and experiences of illness from birth until the age of 11 months were collected using a questionnaire. Thereafter the infants were followed prospectively from the age of 11 to 14 months using diary cards. The diary data consisted of 1) selected symptoms, 2) doctor-contacts and 3) parent-rated illness severity, information used to form three aspects of a frequently ill child. The analyses explore associations from the infant data with the three indicators of frequent illness. Results: Experiences of restless sleep, earache, otitis media, penicillin usage and use of medicine associated with illness in infancy were highly associated with factors of excess illness during the follow up period. Disturbed sleep in infancy was the factor with the highest probability of frequent illness as a toddler-an unexpected finding. Experiences of acute otitis media (earache, frequent visits to the doctor and antibiotic treatment) were strongly related to frequent illnesses. Asthma or giving the child medicine correlated with a higher parent-rated frequency of illness later on. Conclusions: Sleep problems in infancy can predict frequent illness episodes later on. In

\footnotetext{
*Funding: Danish research foundation for general practice.
}

clinical practice the GP may benefit from talking about sleep in the consultations in order to learn something more. The three different indicators of frequent illness applied to different aspects of being a frequently ill child.

Keywords: Infants; Toddlers; Parents; GP; Symptoms; Sleep; Recurrent IIIness; Illness

\section{INTRODUCTION}

Some toddlers suffer significantly more episodes of illness than others, which affect the use of health services and the family's daily well-being and routine. Studies of toddlers' frequent diseases have primarily focused on genetic, birth and socio-economic factors. Disturbed sleep, ear symptoms/diseases and use of medicine seem to be predictors of frequent episodes of illness.

Parents of infants suffering frequent bouts of illness report dissatisfaction with the general practitioner (GP), citing a lack of acknowledgment of their lay observations and accounts of the infant's illness, and a lack of explanations as to why their child is frequently ill [1]. Parents could be worried about the infants' development and health when the infants' are fighting off infections [2].

Both lay-people and health professionals use the terminology "frequently ill", even if there is no clear description of what that means [3-5]. Using the number of physician-attended visits is common but reflects both the illness behaviour of the parents and the health care system of the country. A clinically useful definition of a frequently ill child could make use of several sources, such as the number of days with symptoms of illness, type of specific symptoms or how much medicine is given to the child. It is possible to ask for this information in the medical encounter, but there is no obvious way for the physician to validate that information. By using information on aspects of the child's daily life, such as parental concerns, use of health care services and disruptions to the daily routine for the child and the family, the focus can be shifted from the infant's illness to 
the effect the illness has on the infant, and on the wellbeing of the family and the family's behaviour regarding the illness. According to Gannik, disease is something that occurs physically in the tissues, whereas illness is experienced. In addition, the illness is changed, developed, formed and created by the context and the way it is acted on-described as illness behaviour [6]. Illness behaviour is understood here as the parents' action or reaction to their infant's symptoms, which is found to correlate to the behaviour and expectations of the whole family and its social network when illness emerges in the family $[2,7]$.

Studying parents' reaction to their infant's illness, fever, earache and vomiting were the symptoms most likely to cause parents to rate their infants as ill, and earache was the symptom that most frequently tended to trigger immediate contact with the doctor [8].

It is possible that the parents' experiences with their infant's illness and their interaction with the health care system also account for their later decisions regarding health care for their infant. Research exploring the influences health-care utility and illness experiences in infancy have on later susceptibility to illness is rare [9-11]. No single factor (except immune defects) is yet known to predict frequent illness in later life. However, recurrent otitis media is predicted by the debut of a single otitis media before the age of six months [12]. Other determinants for frequent respiratory symptoms are attending to child day care, passive smoking or having siblings age 1 - 3 years $[12,13]$. The frequent prescription of antibiotics is an indicator of future frequent illness, but may well be the consequence of a high concern about infectious illness that leads to frequent doctor contacts [14]. Is it possible to identify other predictors or illness patterns among infants that can predict frequent illness episodes in later life?

The GPs perspectives: the doctor knows that most children's infections decrease with increasing age $[5,15]$. Being frequently ill may be due to an inherent fragility combined with the interactions of the environment in which the infant lives [4,16-18]. Even if the GP could act as a key person to these children/families by diagnosing the problem, useful clinical interventions targeting the etiology and treatment are underdeveloped, at least when the common infections are involved [7,9]. Understanding the usefulness of parents' own experiences of the illnesses and their interpretation is fundamental in the consultation [2,7]. Many of the parents' were met with sentences such as "it will disappear" or "it is a virus"- but being prepared for those infants/toddlers with frequent illness could allow the GP to improve the premise of the consultation.

The aim of this study was to identify factors in infancy that could predict frequent illness during a later period of time.

\section{METHODS}

\subsection{Sample and Recruitment}

Letters were sent to parents of a birth cohort of 389 infants born in February 2001 within Frederiksborg County, Denmark, in accordance with data extracted from the local National Health Service. The 194 participating infants were followed from birth until the age of 11 months by a questionnaire and (defined as toddlers) from the age of 11 to 14 months using a diary (January, February and March = 90 days). The questionnaire and the diary were filled in by the parents (Figure 1). In order to remind parents during the prospective part of the study to fill in the diaries completely, a letter was sent every 14 days during the three-month follow-up period.

\subsection{Data Collection Methods}

Based on information in the questionnaire, baseline data were collected covering the infants' state of health (symptoms and diagnosis categories, medication usage, number of episodes of illness and GP consultations) and family data (family size, educational level of parents), which were referred to as "Infant data".

The diary data consisted of three one-month calendars with 14 days per page. Each day, the parents could tick whether they considered their infant had experienced any of the following: 1) selected symptoms: crying more than usual, cold/runny nose, not eating normally, not sleeping well, breathing affected, fever, cough, vomiting, diarrhoea, earache; 2) doctor-contacts: telephoned their doctor, visited their doctor, had a home visit, visit from the out-of-hours service, visited a specialist doctor or went to the hospital; 3 ) parent-rated illness severity: how they rated the severity of their infant's illness: $0=$ not ill, $(X)=$ not really ill but not really well either, $X=$ ill, $X X$ $=$ very ill, $\mathrm{XXX}=$ severely ill. The variable $\mathrm{X}, \mathrm{XX}$ and XXX indicated parent-rated illness. The diary data will be referred to as "toddler data". Parents reported the "infant data" before they handed in the "toddler data".

Indicators for being frequently ill from the toddler data during the prospective follow up months were: 1) Presence of 4 or more specific symptoms for $>10$ days, 2) $>4$ doctor contacts and 3) $>10$ days on which the parents considered the infant ill. These thresholds roughly correspond to the $75 \%$ percentile of the distribution over the three-month period recorded.

\subsection{Statistical Methods}

The overall (unadjusted) associations of information from the infant data: family demographic and socioeconomic characteristics, occurrence of symptoms and 


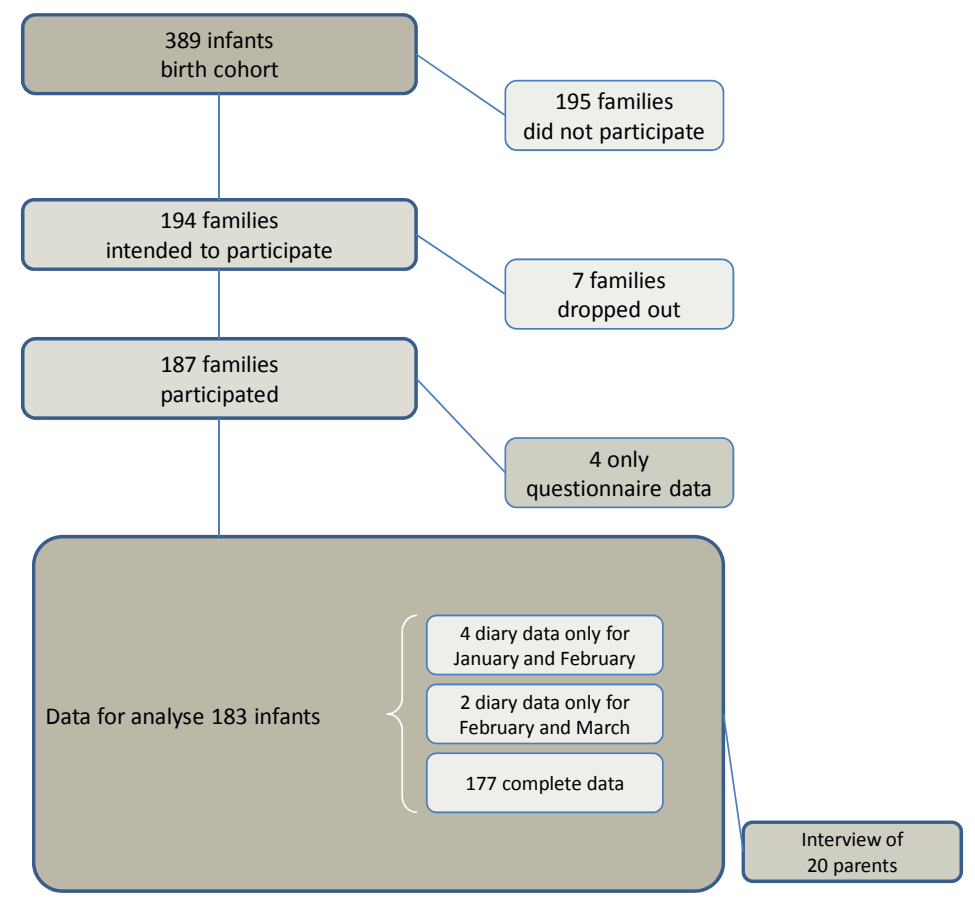

Figure 1. Study population.

disease, doctor visits and medicine use, with the three indicators of frequent illness in the follow up period were tested using chi-squared tests (categorical variables) and t-tests (continuous variables). A p-value of $<0.01$ was considered statistically significant. Multivariately adjusted associations were assessed for each of the three indicators of being frequent ill as the dependent variable, in three logistic regression models: one included as independent variable the indicators of the symptoms in "Infant data", the second included the indicators of disease, use of health care services and medicine and the third included parent-rated general health from the "Infant data" as dependent variables. Additionally, the infant's sex, the parents' age, education and employment (highest of the two parents), housing (apartment vs house), whether the infant was in day care or not, whether there were siblings who were often ill, and how many times the infant was ill during the infant period were included as independent variables in all models. Reduced models were constructed by backwards elimination of the healthcare experience factors $(p<0.05)$ from the full models that included the symptom indicators or the disease and clinical behaviour indicator respectively; the models with parent-rated general health were not reduced. All calculations were done in SAS 9.12.

\section{RESULTS}

\subsection{Study Population}

Of the 389 families invited to participate, 194 accepted
(Figure 1). Seven families dropped out and ten families returned incomplete data, leaving a study population of 183 families with 16,284 days of observation.

The degree of agreement between the three working indicators of being frequent ill as a toddler is illustrated in Figure 2. Fifty-two toddlers were classified with $e x-$ cess symptoms, fifty-four with excess doctor-contacts and fifty toddlers with excess illness. Only about $25 \%$ of the toddlers in each group also featured in the other two groups.

The (unadjusted) associations of the factors of health care and illness experience, family demographic and socio-economic characteristics as infants (retrospective collected questionnaire data) with the three indicators of being frequently ill according to prospectively collected toddler diary data are shown in Table 1. Restless sleep as an infant is significantly related to all of the three indicators for being frequently ill as a toddler (excess symptoms, doctor-contacts and illness episodes). Episodes of earache, otitis media and penicillin usage in infants were related to excess doctor-contacts in toddlers (Table 1). Significant relationships were also found between use of medicine in infants and excess illness in toddlers. The same tendencies were found if the infants had siblings who were often ill, had many doctor visits, used complementary therapies and had good parent-rated health.

Multivariate analyses of the infant data on toddler data adjusted for family demographics and socio-economic factors are shown in Table 2. Restless sleep in infants was significantly related to all indicators for frequently 
Table 1. The associations of family demographic and socio-economic characteristics and incidence of symptoms, disease, doctor visits and medicine use in the first 11 months of life with the three indicators of excess illness in months $11-14$

\begin{tabular}{|c|c|c|c|c|c|c|c|c|c|c|c|}
\hline \multicolumn{12}{|c|}{ Toddlers data } \\
\hline & \multicolumn{5}{|c|}{ 1) 4 or more symptoms } & \multicolumn{3}{|c|}{ 2) Doctor visits } & \multicolumn{3}{|c|}{ 3) Parent-rated illness } \\
\hline & Missing & Total & $\leq 10$ days & $>10$ days & & $\leq 4$ times & $>4$ times & & $\leq 10$ days & $>10$ days & \\
\hline Infants data & & $n=183$ & $n=131$ & $n=52$ & & $n=129$ & $n=54$ & & $n=133$ & $n=50$ & \\
\hline & $n$ & $n(\%)$ & $n(\%)$ & $n(\%)$ & $\mathrm{p}^{2}$ & $n(\%)$ & $n(\%)$ & $\mathrm{p}^{2}$ & $n(\%)$ & $n(\%)$ & $\mathrm{p}^{2}$ \\
\hline Socio-demographics & & & & & & & & & & & \\
\hline Sex of the child (boy) & 0 & $102(55.7)$ & $70(53.4)$ & $32(61.5)$ & 0.32 & $73(56.6)$ & $29(53.7)$ & 0.72 & $75(56.4)$ & $27(54.0)$ & 0.77 \\
\hline Nuclear family & 0 & 177 (96.7) & $126(96.2)$ & $51(98.1)$ & 0.52 & $123(95.4)$ & $54(100.0)$ & 0.11 & $129(97.0)$ & $48(96.0)$ & 0.74 \\
\hline Age parent $(s)^{1}$ & 0 & & & & 0.50 & & & 0.64 & & & 0.76 \\
\hline$\leq 30$ years & & $42(23.0)$ & $32(24.4)$ & $10(19.2)$ & & $32(24.8)$ & $10(18.5)$ & & $30(22.6)$ & $12(24.0)$ & \\
\hline $31-39$ years & & $120(65.6)$ & $86(65.7)$ & $34(65.4)$ & & $83(64.3)$ & $37(68.5)$ & & $89(66.9)$ & $31(62.0)$ & \\
\hline$\geq 40$ years & & $21(11.4)$ & $13(9.9)$ & $8(15.4)$ & & $14(10.9)$ & $7(13.0)$ & & $14(10.5)$ & $7(14.0)$ & \\
\hline${\text { Education parent }(\mathrm{s})^{1}}^{1}$ & 0 & & & & 0.55 & & & 0.29 & & & 0.61 \\
\hline$\leq 12$ years & & $9(4.9)$ & $7(5.3)$ & $2(3.8)$ & & $8(6.2)$ & $1(1.9)$ & & $7(5.3)$ & $2(4.0)$ & \\
\hline $13-14$ years & & $63(34.4)$ & $42(32.1)$ & $21(40.4)$ & & $41(31.8)$ & $22(40.7)$ & & $43(32.3)$ & $20(40.0)$ & \\
\hline$\geq 15$ years & & $111(60.7)$ & $82(62.6)$ & $29(55.8)$ & & $80(62.0)$ & $31(57.4)$ & & $83(62.4)$ & $28(56.0)$ & \\
\hline Profession parent $(\mathrm{s})^{1}$ & 0 & & & & 0.99 & & & 0.90 & & & 0.67 \\
\hline Self-employed & & $51(27.9)$ & $36(27.5)$ & $15(28.9)$ & & $38(29.5)$ & $13(24.1)$ & & $35(26.3)$ & $16(32.0)$ & \\
\hline Employee (high) & & $29(15.9)$ & $20(15.3)$ & $9(17.3)$ & & $20(15.5)$ & $9(16.7)$ & & $21(15.8)$ & $8(16.0)$ & \\
\hline Employee (middle) & & $40(21.9)$ & $29(22.1)$ & $11(21.1)$ & & $26(20.2)$ & $14(25.9)$ & & $27(20.3)$ & $13(26.0)$ & \\
\hline Employee (basic) & & $53(29.0)$ & $39(29.8)$ & $14(26.9)$ & & $38(29.5)$ & $15(27.8)$ & & $42(31.6)$ & $11(22.0)$ & \\
\hline Employee (other) & & $10(5.5)$ & $7(5.3)$ & $3(5.8)$ & & $7(5.4)$ & $3(5.6)$ & & $8(6.0)$ & $2(4.0)$ & \\
\hline Housing (apartment) & 0 & $25(13.7)$ & $16(12.2)$ & $9(17.3)$ & 0.37 & $20(15.5)$ & $5(9.3)$ & 0.26 & $16(12.0)$ & $9(18.0)$ & 0.29 \\
\hline \multicolumn{12}{|c|}{ Health history (in the first 11 months of the infant's life) } \\
\hline Episodes of illness & 2 & & & & 0.11 & & & 0.007 & & & 0.13 \\
\hline Never & & $17(9.4)$ & $16(12.4)$ & $1(1.9)$ & & $14(11.0)$ & $3(5.6)$ & & $15(11.4)$ & $2(4.1)$ & \\
\hline $1-2$ times & & $81(44.8)$ & $59(45.7)$ & $22(42.3)$ & & $65(51.2)$ & $16(29.6)$ & & $63(47.7)$ & $18(36.7)$ & \\
\hline 3 - 4 times & & $59(32.6)$ & $38(29.5)$ & $21(40.4)$ & & $36(28.4)$ & $23(42.6)$ & & $38(28.8)$ & $21(42.9)$ & \\
\hline$>4$ times & & $24(13.2)$ & $16(12.4)$ & $8(15.4)$ & & $12(9.4)$ & $12(22.2)$ & & $16(12.1)$ & $8(16.3)$ & \\
\hline Siblings who are often ill & 2 & $35(19.3)$ & $19(14.7)$ & $16(30.8)$ & 0.013 & $22(17.2)$ & $13(24.5)$ & 0.26 & $20(15.3)$ & $15(30.0)$ & 0.023 \\
\hline Daycare outside the home & 0 & $60(32.8)$ & $42(32.1)$ & $18(28.4)$ & 0.74 & $39(30.2)$ & $21(38.9)$ & 0.26 & $39(29.3)$ & $21(42.0)$ & 0.10 \\
\hline \multicolumn{12}{|c|}{ Symptoms (in the first 11 months of the infant's life) } \\
\hline Fever & 0 & $150(82.0)$ & $103(78.6)$ & $47(90.4)$ & 0.062 & $106(82.2)$ & $44(81.5)$ & 0.91 & $106(79.7)$ & $44(88.0)$ & 0.19 \\
\hline Cough & 0 & $140(76.5)$ & $101(77.1)$ & $39(75.0)$ & 0.76 & $99(76.7)$ & $41(75.9)$ & 0.91 & $100(75.2)$ & $40(80.0)$ & 0.49 \\
\hline Vomiting & 0 & $61(33.3)$ & $42(32.1)$ & $19(36.5)$ & 0.56 & $42(32.6)$ & $19(35.2)$ & 0.73 & $42(31.6)$ & $19(38.0)$ & 0.41 \\
\hline Diarrhoea & 0 & $88(48.1)$ & $60(45.8)$ & $28(53.8)$ & 0.33 & 64 (49.6) & $24(44.4)$ & 0.52 & $61(45.9)$ & $27(54.0)$ & 0.33 \\
\hline Rash & 0 & $47(25.7)$ & $31(23.7)$ & $16(30.8)$ & 0.32 & $31(24.0)$ & $16(29.6)$ & 0.43 & 30 (22.6) & $17(34.0)$ & 0.11 \\
\hline Wheezing & 0 & $58(31.7)$ & 37 (28.2) & $21(40.4)$ & 0.11 & $40(31.0)$ & $18(33.3)$ & 0.76 & $38(28.6)$ & $20(40.0)$ & 0.14 \\
\hline Earache & 0 & $44(24.0)$ & $27(20.6)$ & $17(32.7)$ & 0.085 & $21(16.3)$ & $23(42.6)$ & $<.001$ & $31(23.3)$ & $13(26.0)$ & 0.70 \\
\hline
\end{tabular}

${ }^{1}$ if more than one parent, this is the maximum over both parents; ${ }^{2} \mathrm{p}$-value of a chi-squared test. 
Table 2. Multivariate associations of symptoms, disease and clinical behaviour, and parent-rated general health in the first 11 months of life $=$ infants data with the three measures of excess illness later on $=$ toddlers data.

\begin{tabular}{|c|c|c|c|c|c|c|}
\hline \multirow{3}{*}{ Infants data } & \multicolumn{6}{|c|}{ Toddlers data } \\
\hline & \multicolumn{2}{|c|}{ 1) 4 or more symptoms $>10$ days } & \multicolumn{2}{|c|}{ 2) Doctor visits $>4$ times } & \multicolumn{2}{|c|}{ 3) Parent-rated illness $>10$ days } \\
\hline & OR $(95 \% \mathrm{CI})$ & p-value & OR $(95 \% \mathrm{CI})$ & $\mathrm{p}$-value & OR $(95 \% \mathrm{CI})$ & p-value \\
\hline \multicolumn{7}{|l|}{ Symptoms } \\
\hline Earache & & & $3.71(1.48-9.31)$ & 0.0052 & & \\
\hline A cold/a running nose & & & $0.20(0.05-0.90)$ & 0.0353 & & \\
\hline Restless sleep & $3.99(1.56-10.16)$ & 0.0038 & $2.63(1.06-6.54)$ & 0.0370 & $2.97(1.20-7.34)$ & 0.0188 \\
\hline Allergic reaction & $3.94(1.03-15.13)$ & 0.0456 & & & & \\
\hline \multicolumn{7}{|c|}{ Disease and clinical behaviour } \\
\hline Bronchitis & & & & & $6.85(1.64-28.55)$ & 0.0082 \\
\hline Nature medicine & $3.49(1.01-12.06)$ & 0.0484 & & & & \\
\hline Penicillin & & & $2.68(1.21-5.93)$ & 0.0148 & & \\
\hline
\end{tabular}

Note: for each of the measures of excess illness at one year three logistic regression models were investigated, one including the indicators for the symptoms, one including the indicators for disease and clinical behaviour (indicators for Cold and Fever cramps were not included in the models as only very few children presented with Fever cramps and very few did not present with Cold) and one including parent-rated general health. Each model additionally included the child's sex, the parent's age, education and employment (highest of the two parents), housing (apartment vs house), whether the child goes to daycare, whether there are siblings and siblings that are often ill, and how many times the child was ill in the first 11 months. A reduced model was constructed by backwards elimination from the full model of the symptom indicators or the disease and clinical behaviour indicators respectively until all are significant at a $5 \%$ level; the model with parent-rated general health was not reduced. Only the symptoms and disease/clinical behaviours that were in one of the reduced models are reported in the table; parent-rated health was not significant in any of the models and is therefore not listed in the table.

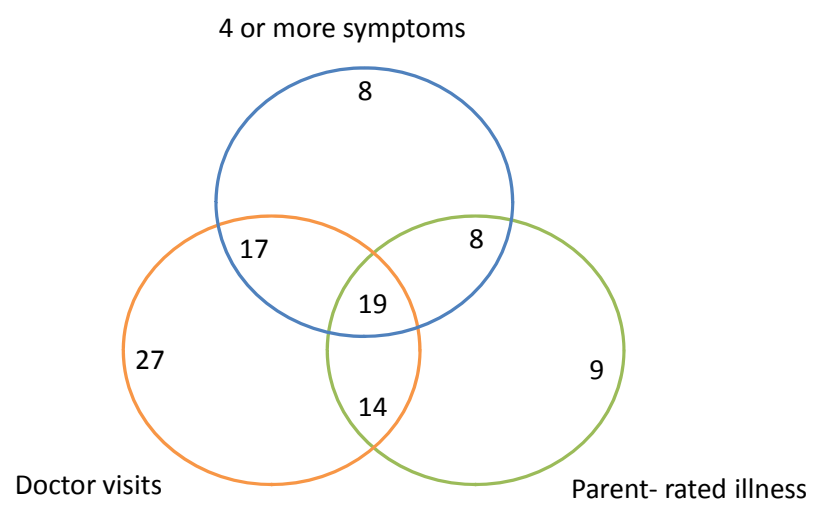

Figure 2. Venn diagram for the three indicators of frequent illness. N: 183, Toddlers with 4 or more symptoms: 52, Parentrated illness: 50, Doctor visits: 77 and Toddlers without symptoms or illness or doctorcontacts: 4 .

ill toddlers (Table 2). Penicillin usage and earache in infants increased the odds ratio of excess doctor-contacts in toddlers. On the other hand, it was found that having a cold in infancy was related to a lower risk of doctor contacts for toddlers. Bronchitis in infancy was associated with excess illness in toddlers. Allergic reactions and the use of complementary medicine were also associated with a higher risk of excess symptoms in toddlers (Table 2).

\section{DISCUSSION}

The main findings were that some specific factors associated with illness in infancy were highly associated with factors of excess illness for another time period ahead. Frequent episodes of illness in infancy were more often followed by frequent episodes of illness as toddler, regardless of the type of measurement. The strongest association was between disturbed sleep and frequent illness later on. While common colds in infancy reduced the risk of excessive illness in toddlers, allergy, earache and antibiotic usage were correlated with frequent illnesses in toddlers.

\subsection{IIIness Assessments}

In our study the parents assessed the infants' symptoms. It is well known that the assessment of symptoms and illness, as well as the amount of doctor contacts, are highly individual and are influenced by the parents' experience and illness behavior [7]. People interpret symptoms and create meaning on the basis of their social and cultural background and experiences [2]. In this process manifold perspectives on illness can arise. Our results and the three indicators of frequent illness support Gannik's situational disease model, in which the parents' behaviour concerning their infants' illness is understood, shaped and handled in the context of the family [6].

\subsection{Frequently III}

We use the term "excess illness" for the toddlers crossing the $75 \%$ percentile for the three indicators. Only $25 \%$ of the toddlers featured in the other groups, although we had expected a stronger match. One explanation could be that the impact of the illness and lay peo- 
ple's understanding of the illness differ from the doctors' perception of these - as described by Kleinman and illustrated below [11].

We found that bronchitis, but not otitis media, was significant for the indicator excess illness. This may show that some diseases are experienced as worse than others, not from a biomedical point of view but in terms of how the daily lives of the infant and family are affected [19]. According to Gannik, the parents' experience of the illness also depends on whether the infant's signs or symptoms can be contained within the situation [6]. An Infant with otitis media often cries and may be difficult to comfort, but the episodes are of short duration, in contrast to bronchitis, in which symptoms linger, are recurrent, unpredictable and need medication [15].

Our finding that penicillin treatment increased the likelihood of excess doctor-contact was expected, as doctor contacts are linked with the experience of illness, parents' socio-economic status, health and the use of health care $[8,18]$. Earache is a strong trigger for excess doctor-contact $[20,21]$ as parents expect a possible diagnosis of otitis to be treated by antibiotics. Furthermore, seeing a doctor is linked with an increased risk of antibiotic prescription [22]. The opposite could also be the case as early antibiotic treatment alters the ecological balance of the microbiological flora in the intestine which makes the child more susceptible to infections as the microbes in the intestine affect the immune system, the so-called microbiome [23]. Reverse contact patterns were found for "having a cold". A cold is, according to parents, just part of daily life $[19,21]$.

\subsection{Disturbed Sleep}

This study found that disturbed sleep can be added to the list of predictors of frequent illness. Research investigating this topic is rare. A sick infant with disturbed sleep can have a severe impact on a family's everyday life [19]. Our findings of disturbed sleep in infants and excess illness in toddlers could be explained physiologically. Disturbed sleep interferes with systems within the body e.g. the psycho-neuro-immunological system [24] and the circadian rhythm [25]. The neuroendocrine system produces hormones such as corticotrophin, melatonin, growth hormone and cortisol, which are sensitive to sleep and regulate cytokine production (il-1 and TNF), leukocyte activities, proliferation and apoptosis. The hormones have specific effects on sleep (increased/decreased sleep influence the sleep architecture ${ }^{1}$ ) and changes in sleep patterns influence the release of these

\footnotetext{
${ }^{1}$ Sleep architecture: is characterized by an optimal length of each sleep stage. The sleep stages: non-rapid-eye-movements sleep (4 stages) and non-rapid-eye-movements sleep (1 stage) are characterized by the frequency and amplitudes of EEG patterns and length of each sleep stage.
}

hormones [25-29]. Infections stimulate the inflammatory cytokines, which change sleep patterns, and a febrile host response leads to elevated cortisol [24].

In human experiments with induced influenza virus and rhinovirus, sleep was significantly disrupted [29]. Illness is a stressful event for the infant, illustrated by the infant's disturbed sleep architecture and higher cortisol levels [25]. This is especially interesting with regard to infants as it is still a matter of discussion at what age infants establish the cortisol circadian rhythm [26,28]. Infants with colic symptoms display disturbed sleep architecture and sleep less, and this might be associated with a disruption or delay in the establishment of a circadian sleep-wake rhythm [30]. One might think that recurrent illnesses in infants affect the infant's sleep architecture. We think there could be a connection between a delay in establishing the personal sleep-wake circadian rhythm owing to (or following) recurrent episodes of illness around the time when the circadian rhythms are being stabilized in the infant.

New research found that there probably is an association between stress in childhood and the onset of immune mediated disease [31-33] and maybe the link is that bad sleep is a stress situation to the infant which can cause risk of infections. A study supports this view, children age 7 - 10 with bad sleep (sleep bruxism) were also more likely to have chronic illness, allergic rhinitis, asthma or upper respiratory tract infections [34].

\subsection{Strengths and Limitations of the Study}

The prospective data collection, which used diary cards, gives a comprehensive picture of the toddler's illnesses as experienced every day during a longer period. Symptoms experienced during the first 11 months (collected by a questionnaire) may on the other hand be underreported, according to recall bias. Some symptoms, such as earache, may be difficult to interpret in infants. Neither information from the questionnaire nor the diaries was compared with medical journal data.

The population was mainly from the middle class, which corresponds to the residents of Frederiksborg County. Of the invited parents only $47 \%$ agreed to participate, while another $20 \%$ of the responders declined to participate owing to lack of time or to the fact that they were already participating in an investigation [9]. However, among those participating, there was a high response rate to both the questionnaire and the diariesand this boosted a high validity to the data. The upkeep of a three-month diary is demanding and may have influenced the selection of parents. Parents from a lower social class may have had a higher use of the health care system, but results according to consultations pattern based on social class are conflicting [9]. 


\subsection{Implications for Clinical Practice}

Disturbed sleep during an infant's first year may be more important than previously understood and the GP should ask about it, especially if the infant presents with recurrent episodes of illness. During prophylactic child health care the GP has a good opportunity to discuss sleep and its influence on the child's health. Whether advice to the parents regarding sleep could help the infant to escape frequent episodes of illness later is something that remains to be proven. We call for further research concerning the association between child/parents' sleep patterns and infections diseases and other health effects as toddlers.

\section{ETHICAL APPROVAL}

The Danish Local Ethics Committee of Frederiksborg County. Journal number 2001-1-62G.

\section{ACKNOWLEDGEMENTS}

We would like to acknowledge the support of the parents who took part in this study.

\section{REFERENCES}

[1] Ertmann, R.K., Reventlow, S. and Soderstrom, M. (2011) Is my child sick? Parents' management of signs of illness and experiences of the medical encounter: Parents of recurrently sick children urge for more cooperation. Scandinavian Journal of Primary Health Care, 29, 23-27.

[2] Helman, C.G. (1984) Culture, health and illness. Arnold, London.

[3] Jasenak, M., et al. (2011) Recurrent respiratory infections in children-Definition, diagnostic approach, treatment and prevention. Bronchitis. InTech, 119-148.

http://cdn.intechopen.com/pdfs/17357/InTech-Recurrent respiratory_infections_in_children_definition_diagnostic approach treatment and prevention.pdf

[4] De, M.M. and Ballotti, S. (2007) The child with recurrent respiratory infections: Normal or not? Pediatric Allergy and Immunology, 18, 13-18.

doi:10.1111/j.1399-3038.2007.00625.x

[5] Johnson, C.M. (2008) Children's health: When to worry about frequent illness.

http://www.pta.org/ocm childrens health_when to worr y_about_frequent_illness.asp.

[6] Gannik, D.E. (1995) Situational disease. Family Practice, 12, 202-206. doi:10.1093/fampra/12.2.202

[7] Kleinman, A. (1988) The Illness Narratives: Suffering, healing \& the human condition. Basic Books, New York.

[8] Janicke, D.M., Finney, J.W. and Riley, A.W. (2001) Children's health care use: A prospective investigation of factors related to care-seeking. Medical Care, 39, 990-1001. doi:10.1097/00005650-200109000-00009

[9] Uijen, J.H., van Duijn, H.J., Kuyvenhoven, M.M., Schel- levis, F.G. and van der Wouden, J.C. (2008) Characteristics of children consulting for cough, sore throat, or earache. The British Journal of General Practice, 58, 248254. doi:10.3399/bjgp08X279751

[10] Dingle, J.H., Badger, G.F. and Jordan, W.S. (1964) Illness in the home. A study of 25,000 illnesses in a group of cleveland families. Western Reserve University, Cleveland.

[11] Söderström, M., Hovelius, B. and Prellner, K. (1991) Respiratory tract infections in children with recurrent episodes as preschoolers. Acta Paediatrica Scandinavia, 80, 688695.

[12] Prellner, K., Kalm, O. and Harsten, G. (1992) Middle ear problems in childhood. Acta Otolaryngology, 493, 93-98.

[13] Douglas, R.M., Woodward, A., Miles, H., Buetow, S. and Morris, D. (1994) A prospective study of proneness to acute respiratory illness in the first two years of life. International Journal of Epidemiology, 23, 818-826.

[14] Andre, M., Hedin, K., Hakansson, A., Molstad, S., Rodhe, N. and Petersson, C. (2007) More physician consultations and antibiotic prescriptions in families with high concern about infectious illness-Adequate response to infection-prone child or self-fulfilling prophecy? Family Practice, 24, 302-307. doi:10.1093/fampra/cmm016

[15] Asmussen, L., Olson, L.M. and Sullivan, S.A. (1999) "You have to live it to understand it": Family experiences with chronic otitis media in children. Ambul Child Health, 5, 303-312.

[16] von Linstow, M.L., Holst, K.K., Larsen, K., Koch, A., Andersen, P.K. and Hogh, B. (2008) Acute respiratory symptoms and general illness during the first year of life: A population-based birth cohort study. Pediatric Pulmonology, 43, 584-593. doi:10.1002/ppul.20828

[17] Li, V.G., Malaponte, G., Bevelacqua, V., Messina, A., Bianca, S., Mazzarino, M.C., et al. (2003) Persistent high plasma levels of interleukins 18 and 4 in children with recurrent infections of the upper respiratory tract. Transplantation Proceedings, 35, 2911-2915. doi:10.1016/j.transproceed.2003.10.024

[18] Saxena, S., Majeed, A. and Jones, M. (1999) Socioeconomic differences in childhood consultation rates in general practice in England and Wales: Prospective cohort study. British Medical Journal, 318, 642-646. doi:10.1136/bmj.318.7184.642

[19] Ertmann, R.K. (2007) What makes parents consult a physician? Ph.D. Thesis, Research Unit for General Practice in Copenhagen, Copenhagen.

[20] Ertmann, R.K., Siersma, V., Reventlow, S. and Soderstrom, M. (2011) Infants' symptoms of illness assessed by parents: Impact and implications. Scandinavian Journal of Primary Health Care, 29, 67-74. doi: 10.3109/02813432.2011.576863

[21] Saunders, N.R., Tennis, O., Jacobson, S., Gans, M. and Dick, P.T. (2003) Parents' responses to symptoms of respiratory tract infection in their children. Canadian Medical Association Journal, 168, 25-30.

[22] Mölstad, S. (1990) Antibiotics usage and betalactamase production in respiratory tract bacteria. University of Lund, Lund. 
[23] Getz, L., Kirkengen, A.L. and Ulvestad, E. (2011) The human biology - Saturated with experience. Tidsskrift for Den norske Legeforening, 131, 683-687.

[24] Steiger, A. (2002) Sleep and the hypothalamo-pituitaryadrenocortical system. Sleep Medicine Reviews, 6, 125138. doi:10.1053/smrv.2001.0159

[25] Raikkonen, K., Matthews, K.A., Pesonen, A.K., Pyhala, R., Paavonen, E.J., Feldt, K., et al. (2010) Poor sleep and altered hypothalamic-pituitary-adrenocortical and sympathoadrenal-medullary system activity in children. The Journal of Clinical Endocrinology \& Metabolism, 95, 22542261. doi:10.1210/jc.2009-0943

[26] De, W.C., Zijl, R.H. and Buitelaar, J.K. (2003) Development of cortisol circadian rhythm in infancy. Early $\mathrm{Hu}-$ man Development, 73, 39-52. doi:10.1016/S0378-3782(03)00074-4

[27] Dijk, D.J. and Czeisler, C.A. (1995) Contribution of the circadian pacemaker and the sleep homeostat to sleep propensity, sleep structure, electroencephalographic slow waves, and sleep spindle activity in humans. The Journal of Neuroscience, 15, 3526-3538.

[28] Kirschbaum, C. and Hellhammer, D.H. (1989) Salivary cortisol in psychobiological research: An overview. Neuropsychobiology, 22, 150-169. doi:10.1159/000118611

[29] Smith, A. (1992) Sleep, colds and performance. In: Brough- ton, R. and Ogilvie, R.D., Eds., Sleep, Arousal, and Performance, Birkhüser, Boston, 233-234.

[30] White, B.P., Gunnar, M.R., Larson, M.C., Donzella, B. and Barr, R.G. (2000) Behavioral and physiological responsivity, sleep, and patterns of daily cortisol production in infants with and without colic. Child Development, 71, 862-877. doi:10.1111/1467-8624.00196

[31] Caserta, M.T., O’Connor, T.G., Wyman, P.A., Wang, H., Moynihan, J., Cross, W., et al. (2008) The associations between psychosocial stress and the frequency of illness, and innate and adaptive immune function in children. Brain Behavior and Immunity, 22, 933-940. doi:10.1016/j.bbi.2008.01.007

[32] McEwen, B.S. (2000) Allostasis and allostatic load: Implications for neuropsychopharmacology. Neuropsychopharmacology, 22, 108-124. doi:10.1016/S0893-133X(99)00129-3

[33] Nielsen, N.M., Hansen, A.V., Simonsen, J. and Hviid, A. (2012) Stressful life events in childhood and risk of infectious disease hospitalization. European Journal of Pediatrics, 171, 173-179. doi:10.1007/s00431-011-1498-2

[34] Lam, M.H., Zhang, J., Li, A.M. and Wing, Y.K. (2011) A community study of sleep bruxism in Hong Kong children: Association with comorbid sleep disorders and neurobehavioral consequences. Sleep Medicine, 12, 641-645. 